\title{
Indonesian plastic surgeons' attitude during early period of the COVID-19 pandemic
}

\section{Theddeus Octavianus Hari Prasetyono}

Division of Plastic Surgery, Department of Surgery, Cipto Mangunkusumo Hospital, Faculty of Medicine Universitas Indonesia, Jakarta, Indonesia

\begin{abstract}
Background: This study aims to report how the practice of plastic surgeons and their attitude was during the first measure period of coronavirus disease 2019 (COVID-19) pandemic.

Methods: A survey study was held among members of the Indonesian Association of Plastic Reconstructive and Aesthetic Surgeons during week 5 after the first report of COVID-19. A 10 multiple-choice questions (MCOs) and 1 essay covered key questions on the area of surgery and operating room, clinics, internal meeting, and consultation. The only open-ended question relates to the last MCO addresses a future "flipped" medical practice.

Results: Response rate was $45.6 \%$ among 228 members, with $89.4 \%$ did no practice or limited their service to emergency and urgent cases only. Only $1.9 \%$ kept their official meeting as usual, while the majority modified it. The practice in the operating theatre and clinic were also altered to comply with the measures; with $21.2 \%$ from the total respondents only allowed patients with exposure to come for visit after taking 14 days of self-quarantine. Teleconsultation was practiced by $50 \%$ of the respondents, while $41.3 \%$ agreed and $10.6 \%$ disagreed upon the future "flipped" medical practice.

Conclusion: In general plastic surgeons have made supportive actions during the pandemic. Surgery was performed with all precautions at the utmost as a reflection of high alert of viral infection. Teleconsultation has been embraced via existing social media. Agreement upon the future "flipped" medical practice is reasonable. All in all, the actions were considered as most relevant.
\end{abstract}

Keywords: Pandemics / Surgery, plastic / Surveys and questionnaires / Viruses

\section{INTRODUCTION}

The severe acute respiratory syndrome coronavirus 2 (SARS$\mathrm{CoV}-2$ ) outbreak was initially declared as a public health emergency of international concern on January 30, 2020 by the World Health Organization (WHO) after the first report from

Correspondence: Theddeus Octavianus Hari Prasetyono

Division of Plastic Surgery, Department of Surgery, Cipto Mangunkusumo

Hospital/Faculty of Medicine, Universitas Indonesia, Medical Staff Wing,

A building, 4th Floor, Jl. Diponegoro 71, Jakarta 10430, Indonesia

E-mail: theddeus.h@ui.ac.id

The author thanked the Board of the Indonesian Association of Plastic

Reconstructive and Aesthetic Surgeons (InaPRAS) for allowing the author to reach its members.

Received August 5, 2020 / Revised January 23, 2021 / Accepted February 17, 2021
Wuhan, China, at the end of year 2019 [1]. The emerging disease, later named coronavirus disease 2019 (COVID-19) spread rapidly and was declared a pandemic by WHO on March 11, 2020 [2]. In only just a few weeks, it had a significant impact on the healthcare system of almost all countries affected. Indeed this impact was not restricted to countries with poor healthcare systems; it also paralyzed many developed countries, causing an exponential number of infected people and subsequent mortality $[3,4]$. Furthermore, complex issues arose as a result of the shortage of personal protective equipment, intensive care unit beds, and ventilators [5]. In addition, the socioeconomic impact of government policies on the mobilization of people [6,7] and the current so-called lockdown, along with rapid changes 
in the domestic situation, have forced the doctors, including plastic and aesthetic surgeons to adapt to these new conditions. Indonesia reported its first case of COVID-19 much later than many other countries in the region. Singapore declared its first case on January 23, $2020[8,9]$. the Philippine, on January 30, 2020 [10]; and Malaysia and Thailand, on February 15, 2020 $[11,12]$. The first two cases from Greater Jakarta, the capital city of Indonesia, were announced on March 2, 2020 [8,13]. Many people were not fully aware of how contagious the SARS$\mathrm{CoV}-2$ was, albeit they have watched the news and followed updates on social media regarding countries that were affected by the epidemic earlier, such as Korea, Iran, and Italy [14-16]. People tended to act the same from region-to-region, where they did not believe that their country would see a viral outbreak as severe as those that had been reported in other countries worldwide [6]. This disbelief, and the general feeling of overconfidence led many to underestimate the danger of the outbreak. This phenomenon was observed in Australia, Indonesia, the United States, and many European and South American countries $[17,18]$. The reaction of specialized doctors who are not categorized as the first liners in combating the infectious diseases, including plastic surgeons, was no different to that of the general public. Even when entering the second week after the early cases were announced, most doctors still performed their professional work as usual. In fact, an immense change, which is mostly considered as a false "sudden change" only impacted the doctors' practice in the third week or so.

Hospitals and health institutions anticipate the return of normal practice, including resumption of elective plastic surgery services, in the near future. However, the new normal has to consider the health protocols established by the local government, and these protocols must be implemented for anyone providing or receiving medical services in order to ensure the safety of both medical personnel and patients from the spread of COVID-19.

The duration and frequency of direct meetings between doctors and patients might be one of the factors that increase the spread of COVID-19. The "flipped" medical practice method could be adopted in order to keep meetings between doctors and patients as short as possible but still optimal. The term "flipped" refers to a medical service that is provided via telemedicine, which communication with the patient occurs via video/text/data consultation for history taking and physical examination (inspection only). Moreover, the "flipped" method involves discussion of the supportive examinations and other data taken from laboratory tests and imaging, while also completing electronic paperwork of the necessary documents. Clinical visits are expected to only last a short duration and occur less frequently for confirmation and clinical interventions, either surgically or non-surgically, or both.

This study aimed to report the practice and attitude of plastic surgeons during the first measured period of the COVID-19 pandemic. Although conducted in Indonesia only, this study could provide a representation of how plastic surgeons in general reacted to the current outbreak, in terms of their professional practice, and how they would anticipate potential change or modification in the future practice. Moreover, this study may be used as a representation of how "flipped" medical practice, which is efficient in terms of time and frequency of meetings with patients, could become one of the primary methods of online-based healthcare.

\section{METHODS}

A survey study was conducted among active members of the Indonesian Society of Plastic Reconstructive and Aesthetic Surgeons (InaPRAS) for a short period of time (i.e., 5 days) during the fifth week after the first two cases of COVID-19 were announced in the country (March 2, 2020). The period was considered as the first measure before the second stricter measures were stipulated on April 10, 2020 in Greater Jakarta area as the epicenter of the outbreak. An online questionnaire that took 3-5 minutes to complete was sent to WhatsApp (WA) groups using WhatsApp application (Facebook Inc., Menlo Park, CA, USA) and by e-mail to all members of the society on March 29, 2020. The response submission was concluded on April 3, 2020. There was one plenary WA group, which contained all of the members, and five others smaller groups of specific and disciplined interest in aesthetic and reconstructive surgery. The survey was also sent to the smaller groups with the intention to increase the response rate.

The questionnaire was created using 10 multiple-choice questions (MCQs) and one open-ended question that needed respondents to describe their opinion, based on Google Form format (Google LLC, Mountain View, CA, USA). A short introduction to the aims of the survey was followed by the affiliation and type of work in the plastic surgery field and, subsequently, by key questions on the area of surgery and operating room, clinical/polyclinic, internal meeting, and consultation [19]. The only open-ended question, which related to the last MCQ, addressed the future of "flipped" medical practice (Table 1).

A link was sent to all of the society members in the WA groups, while the same survey form was attached to the body of an e-mail. Both ways of reaching the respondents were created to provide respondents with the simplest possible steps to participate. All in all, respondents needed to perform three steps as 
follows: (1) click the link (in the WA or e-mail), (2) complete the questionnaire, and (3) submit the response. The data are presented as distributive statistics, after scrutinizing the questions that were presented with more than one answer allowed. The written essay was classified into three categories as follows: positive attitude to embrace future "flipped" medical practice, strongly opposed to the practice, and a response in between.

\section{RESULTS}

Among 228 society members, 104 respondents participated in the survey, which showed a response rate of $45.6 \%$. Regarding

Table 1. List of questions

\begin{tabular}{l}
\hline No. Questions \\
\hline 1. What is your job affiliation? \\
2. What is the type of procedure on your current practice? \\
3. Which surgeries and other procedures do you perform during this COVID-19 \\
pandemic period? \\
4. If you operate only certain cases of emergency, what you do with those that \\
you would have operated under normal circumstances and that you do not \\
operate at all? (Just for you who only operate on emergency cases) \\
5. Your practice in the operating room? \\
6. Staff meeting (administrative, managerial, scientific)? \\
7. The organization of clinic/polyclinic? \\
8. Hospital or clinic organization for staff? \\
9. Do you embrace teleconsultation/telemedicine? \\
10. How do you think about the future practice by embracing "flipped" medical \\
and surgical procedures? This flipped practice describes how you would con- \\
sult and screen your patients by on-line and off-line interaction; and take \\
them only for final physical examination, medical and surgical intervention, \\
and reduced or limited follow-up visit. \\
\hline 11. Describe your opinion about the future practice by embracing "flipped" medi- \\
cal and surgical procedures?
\end{tabular}

COVID-19, coronavirus disease 2019. work affiliation, $5.8 \%$ of respondents were affiliated to public hospitals, $11.5 \%$ of private hospital, $52.9 \%$ to combined public and private hospitals, $12.5 \%$ to combined public hospitals and private clinics, $13.5 \%$ to combined private hospitals and clinics, and only $3.8 \%$ to private clinics. When asked about the type of works in terms of the composition of reconstructive and aesthetic surgery, $24 \%$ of the respondents described their work as only reconstructive surgery, 55.9\% reported that their work comprised 3 of 4 reconstructive works and 1 of 4 aesthetic procedures, $11.5 \%$ reported an equal proportion between reconstructive and aesthetic procedures, $4.8 \%$ indicated a tilt toward aesthetic procedures (3/4), and the remaining 3.8\% worked only in the aesthetic field.

The percentage of the respondents who did not perform surgery was $15.4 \%$; $74 \%$ limited the practice to only emergency and urgent cases (Fig. 1). Among those who only performed

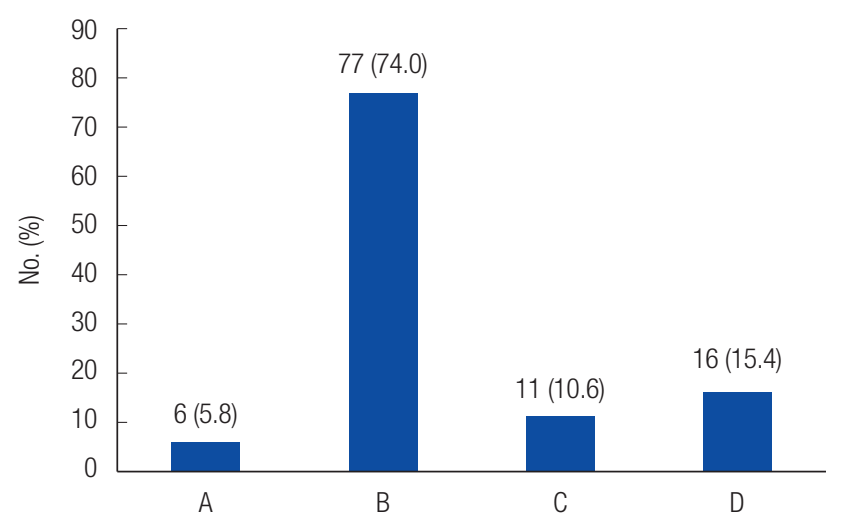

Fig. 1. Surgeries and other procedures performed during coronavirus disease 2019 (COVID-19) pandemic. A, all patients as usual; B, only emergency and urgent (cancer, infection, prevention of severe functional and aesthetic deformity) cases; C, all emergency and non-emergency in outpatient setting (polyclinic); D, none.

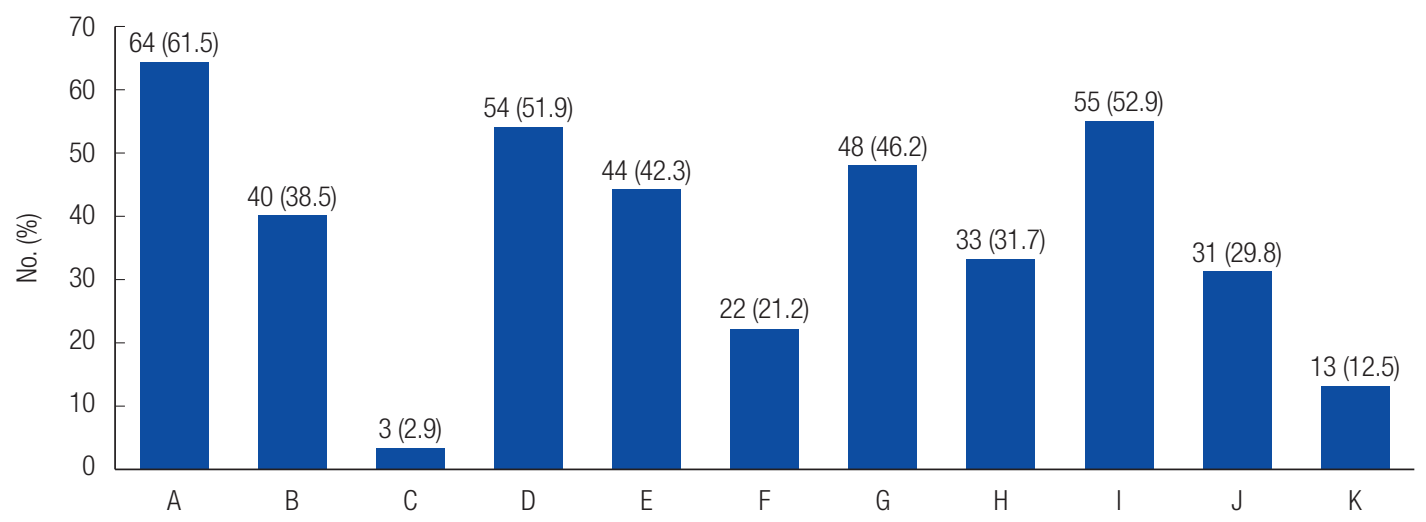

Fig. 2. The practice in the operating room. A, you wear surgical mask; B, you wear N95 mask or equivalent; C, you wear modified mask; D, you wear protective glasses; E, you wear face shield; F, you wear isolation gown (which cover from head to toe); G, you limit number of personnel to minimum in the theatre; $\mathrm{H}$, you bring your cell phone, pen, or other personal belongings into the theatre; I, you cleanse your stuff before going out of the theatre block; J, the coronavirus disease 2019 (COVID-19) patient is operated on in different rooms from the non-COVID-19 patients; K, you do not operate at all. 
emergency surgery, $76.2 \%$ performed conservative treatment, while the remaining $23.8 \%$ referred their cases to other hospitals.

Thirty-one of the 104 respondents selected more than one answer; the majority of their meetings were either cancelled or channeled into chat groups (52.9\%) or organized through videoconference (56.7\%). Furthermore, $18.3 \%$ of respondents limited the number of personnel in their meetings, while $1.9 \%$ respondents managed their business as usual.

Forty plastic surgeons (38.5\%) wore N95 masks in the operating theatre (OT), while $42.3 \%$ wore face shields. $29.8 \%$ indicated that they had an OT dedicated to COVID-19 patients, while $31.7 \%$ still brought their personal belongings, including cell phones, to the OT (Fig. 2). The majority of surgeons took measures to alter the organization of the clinic or polyclinic (of the hospital) to limit contact and exposure (Fig. 3), although only $23.1 \%$ of respondents declared a separate area to limit crossmobilization. Nineteen out of 58 respondents $(21.2 \%$ of the total respondents) only allowed COVID-19 exposed patients to visit after 14 days of self-quarantine. Fig. 4 shows the organization of the staff, in whom almost $90 \%$ wore surgical masks. As many as $34.6 \%$ of surgeons split their teams into groups; and $13.5 \%$ avoided direct contact between different groups of staff. In addition, $44.2 \%$ mentioned that their hospital was provided with a dedicated team for COVID-19 with a quick response system.

In response to the limitations of clinical practice with classical on-site meetings between doctors and patients, 50\% used telemedicine (teleconsultation). When asked about the future practice of "flipped" medical practice, $41.3 \%$ agreed and $10.6 \%$ dis-

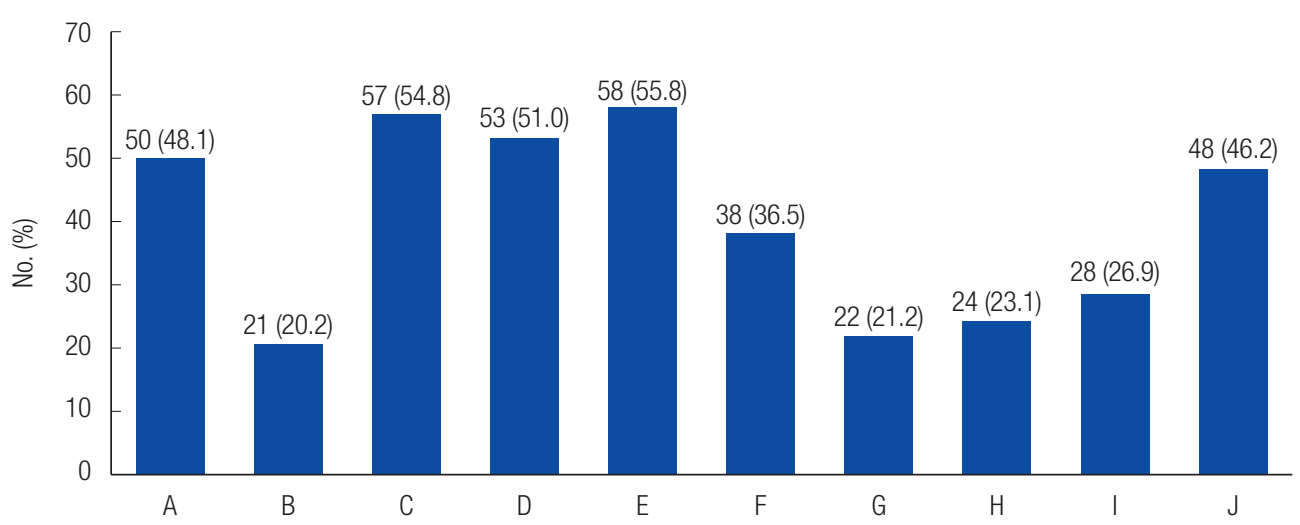

Fig. 3. Organization of clinic/polyclinic. A, you check all visitors by temperature and risk factors (travelling, exposure); B, you check visitors only by temperature; $\mathrm{C}$, you limit number of people accompanying the patients; D, you limit number of patients to consulting; E, you manage patients by appointment; F, you manage patients by appointment and screen them with risk factors in advance; G, you do not take new patients with risk factors unless they have done self-quarantine for 14 days; $\mathrm{H}$, there is separation of area in your hospital (or even clinic) to limit people cross mobilization; I, if you perform surgery on outpatient basis, you rechecked the temperature and risk factors; J, you limits the number of visit per patient in terms of follow-up after surgery.

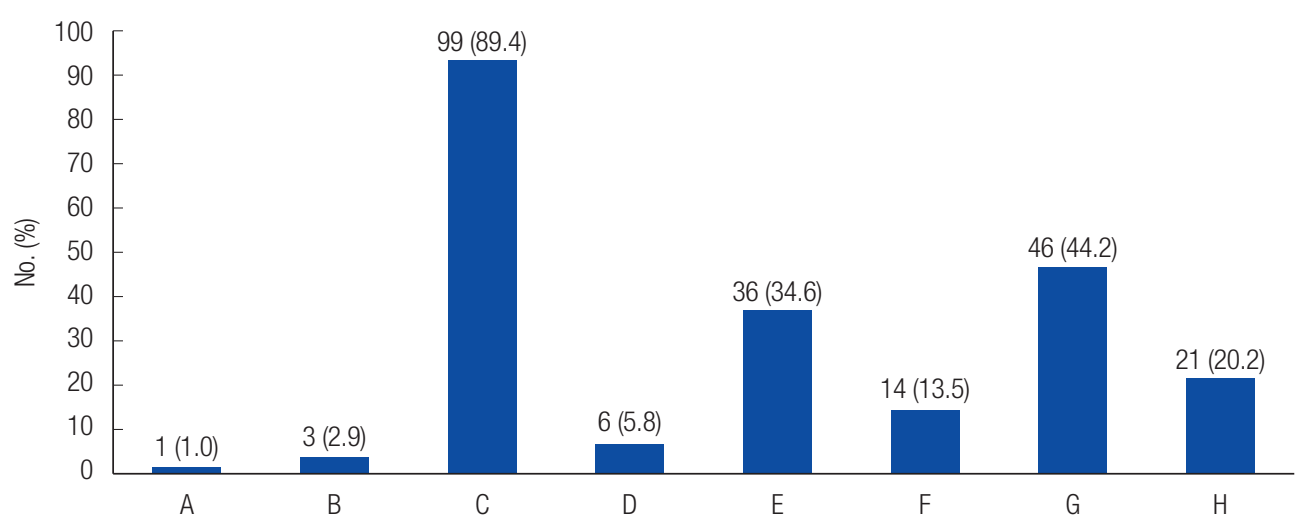

Fig. 4. Organization for staffs. A, staff do not wear mask; B, staff wear mask only in the meeting of a patient contact coronavirus disease 2019 (COVID-19); C, staff wear surgical mask at all times; D, staff wear N95 mask or equivalent at all times; E, your team in hospital is divided into several groups or consultant in charge takes turn; F, your team in hospital is divided into several groups which must not come into contact with each other; G, teams dedicated to COVID-19 including general doctor, pulmonologist, internist, infection specialist can intervene quickly upon request to examine suspected or confirmed cases; $\mathrm{H}$, the teams in the previous choice, if your hospital has, are kept separate from the rest of the service to minimize the risk of cross contamination. 


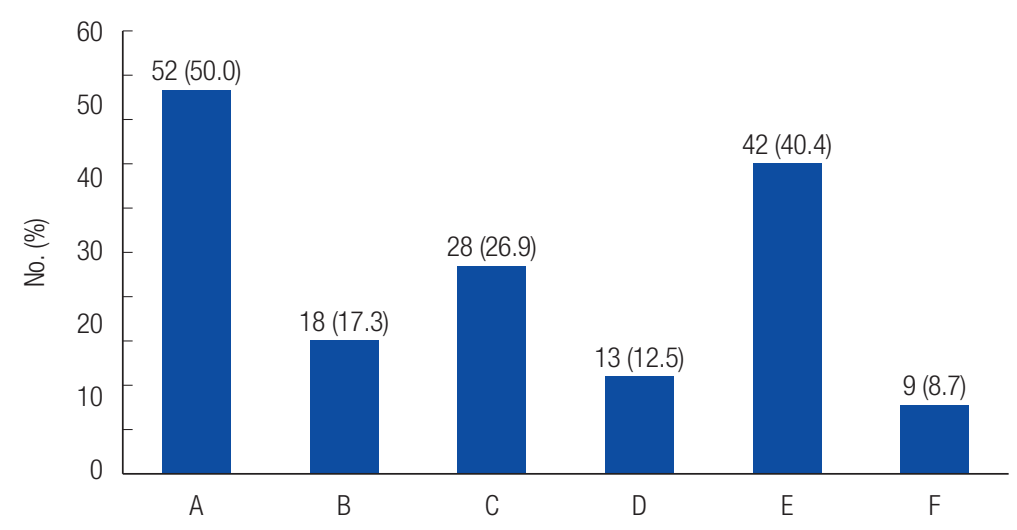

Fig. 5. The attitude to adopt telemedicine/teleconsultation. A, yes; B, no; C, maybe; D, existing platform by third party; E, direct message from existing social media; $F$, you would create your own platform in the future.

agreed (Fig. 5). Fifty-five respondents (52.9\%) provided opinions in the form of a written essay; 14 out of 55 were strongly opposed to the idea, while 15 out of 55 expressed firm agreement.

\section{DISCUSSION}

Of the total respondents, $89.4 \%$ of plastic surgeons took a step back from the clinical practice in the operating and procedural room, either by completely stopping their practice or by only taking emergency and urgent cases. With regard to emergency cases, burns and household or traumatic injuries were the main cases that required patient care at the earliest. Urgent cases might include cases requiring urgent follow-up, those with hematoma or seroma formation, cases of infection, suspected cases of breast implant-associated anaplastic large cell lymphoma, or cases requiring after-surgery care, such as the removal of sutures, correction procedures for complications, wire removal after pinning for hand fracture, and dressing changes after skin graft. In general, plastic surgeons have made supportive actions during the pandemic by relieving pressure on the healthcare system. This attitude is also reflected by the fact that $76.2 \%$ of emergency cases were temporarily converted into conservative treatment.

With regards to the risk that plastic surgeons expose themselves, their team, and family to, $5.8 \%$ of plastic surgeons still performed their work as usual. It is difficult to categorize the surgeons by the type of work they perform since the survey. Although the typical working place of plastic surgeons in Indonesia when referred to the clinic is associated with aesthetic procedures and surgery, it is arguable to point out that the group belonged to the aesthetic group. Moreover, the guideline for plastic surgery practice was only launched by the InaPRAS on at April 15, 2020 [20]. It was expected that the practice of es- thetic surgery and non-surgical procedures would have ceased during the pandemic as a result of the campaigns conducted by national as well as international societies [5,21-23]. Indeed, the cessation of esthetic procedures is in line with the effort to contain the virus and flatten the curve of the outbreaks that was required considering the insufficient measures taken by the government and citizens to anticipate the outbreak. Thus, it will be acceptable to perform aesthetic procedures when the country enters a state of convalescence.

Physical and social distancing $[23,24]$ was generally adhered to by surgeons in hospitals and clinics, with the majority administrative and scientific meetings converted into video conferencing and channeled into social media (with direct messages) and chat groups. This seemed to work well, considering the uptake of staff in virtual meeting rooms and the increase in the number of users of videoconference applications. Indeed, a previous report has shown that the number of users of a particular company provider rose from 10 million to 200 million [25]. Moreover, the learning experience of plastic surgeons with continuing medical education has been almost entirely transformed to virtual rooms $[26,27]$.

Notably, 38.5\% of surgeons reported wearing N95 masks in the OT (Fig. 2) during the time when it had not yet been advised in the country. The standard of personal protective equipment and guidelines for plastic surgery practice were launched by the Ministry of Health on April 12, 2020, and later by InaPRAS $[20,28]$. Despite the fact that the surgeons were performing surgery on non-suspected COVID-19 patients, plastic surgeons also wore face shields, which has become a standard of practice in performing surgery on a patient with suspected COVID-19 or those who had closed contact with a SARSCoV-2 positive person. Procedures that have the potential to generate aerosols, such as drilling for hand and facial bone fracture fixation, absolutely require standard full protection from 
head to toe, since the virus remains viable for 3 hours in the form of aerosol and is found in the nasal cavity at a disproportionately high viral load $[29,30]$.

Of the total respondents, $46.2 \%$ of surgeons reported limiting the practice setting in terms of the number of personal permitted in the OT. Although there has been no standard recommended by the WHO with regard to performing surgery, utmost precaution should be taken until proven unnecessary. Furthermore, surgical teams must be aware of avoiding viral infection by applying all measures at the highest level, including well-protected anesthesia doctors and nurses and the use of negative pressure OTs whenever possible. This is not a question when surgery is to be performed on a positive COVID-19 patient, with which $29.8 \%$ of respondents also mentioned that their facility provided specially dedicated OT. However, the implementation of these preventative measures was let down by the fact that $31.7 \%$ of the surgeons continued to take their personal belongings, including cell phones, into the OT. Although it is unclear whether they covered their belongings to maintain sterility, it is clear that, in general, $52.9 \%$ of respondents cleaned their belongings before exiting the theatre block.

As part of the comprehensive measure in the hospitals and clinics, the practice has been shown to deter cross-viral contamination. Fig. 3 shows that the clinics do not only screen body temperature and history of potential exposure to COVID-19 (48.1\%), but also limit their service by appointment only. Indeed, 38 out of 58 respondents screened their patients by risk factors (history of exposure). The history of exposure cannot be separated from the temperature screening protocols [31]. Furthermore, 19 of 58 respondents imposed strict measures such that patients with exposure were only permitted to visit after 14 days of self-quarantine. This was considered most relevant to the time period when the outbreak was still ongoing and approached its peak. The policy to limit the number of visits per patient was reported to be implemented by $46.2 \%$ of the respondents. Additionally, all staff members at the office were asked to wear mask (95.2\%), which complied with the standard [20,32].

Teleconsultation was embraced by half of the respondents, although the platforms used may have varied. Existing social media, which mainly allows direct messaging, was obviously beneficial for $40.2 \%$ of the respondents, although there were also choices available including existing start-ups in the country. If we combine the $26.9 \%$ of respondents who might consider using telemedicine in their practice and those who strongly agreed upon telemedicine, the number becomes $89.4 \%$. Some of the respondents who positioned themselves in this "pros" group were considering practicing the "flipped" medical prac- tice. Although flipped classrooms in medical education have been popular in the past decade [33-35]. "flipped" medical practice is not well reported in the literature. However, in this digital age, it is likely some doctors have been practicing "flipped" medicine in part without realizing the greater possibility of it being fully embraced.

The opinions of the respondents who strongly agreed included some advantages they have experienced, e.g., "patients who were further away geographically found this practice more convenient, which led to a better experience and limited the number of physical visits to only necessary check-ups and saved more time and energy, and for some cases, it was more effective and efficient." In addition, respondents also shared: "Since the pandemic, strangely enough, there are even more demands on aesthetic procedures; patients say now that they do not have to work and have free time, they can rest and recover." The professional relationship with patients could also be customized in terms of time, duration, frequency, and also in private or a group mode. Indeed, the latter could be a great opportunity to keep in contact with patients, while hoping for better situations that might allow doctors to resume their service. Conversely, some draconian oppositions shared by the respondents included "it is probable that some patients might get the wrong idea during online consultation," "it is unethical; I would not do that for my family," "face-to-face consultation remains the ideal interaction between doctor and patient."

The current COVID-19 pandemic can provide us with important lessons, in part as a result of its origin from global unpreparedness [36]. Thus, it is mandatory for professionals such as plastic surgeons to anticipate the future properly. Recommendations for future practice may include the following: virtual consultation, off- and on-line sessions [37-39] for synchronous group consultation by a medical team, e-documents preparation (e-paperwork) proceeded with lengthy informed consent and strong legal standing (although this may vary from country to country) [40], thorough and complex history tracking, necessary laboratory tests, shorter onsite consultation and physical examination, fewer follow-up visits, and electronic feedback and aftercare digital communication by customer service.

This descriptive study has some limitations. First, there was bias in the time frame; the survey was conducted over a limited time period and might not reflect the dynamic changes during the very fast situational changes, both domestically and internationally. Second, this survey did not address the role of plastic surgeons in the rally as part of a community by taking part in overcoming the viral outbreak. Many plastic surgeons took an active role in supporting the government and people's efforts to 
contain the viral outbreak, in addition to organizing webinars, either for their peers or lay people. Third, it is undeniable that the survey only targeted members of a single society in a country that might not be representative of all populations across nations.

In summary, Indonesian plastic surgeons have played important roles as second liners in mitigating the pandemic. Compliance with the call to only perform necessary surgeries during the critical time of viral incubation was considered good, with almost $90 \%$ of surgeons stepping back from business as usual. The plastic surgeons also coped with new safety measures required to provide service for the urgent and emergency cases. The future of changing medical practice has also been taken into account by embracing technology during and after this life-changing pandemic.

\section{NOTES}

\section{Conflict of interest}

No potential conflict of interest relevant to this article was reported.

\section{ORCID}

Theddeus Octavianus Hari Prasetyono https://orcid.org/0000-0003-3675-4309

\section{REFERENCES}

1. Wu YC, Chen CS, Chan YJ. The outbreak of COVID-19: an overview. J Chin Med Assoc 2020;83:217-20.

2. Sarac NJ, Sarac BA, Schoenbrunner AR, Janis JE, Harrison RK, Phieffer LS, et al. A review of state guidelines for elective orthopaedic procedures during the COVID-19 outbreak. J Bone Joint Surg Am 2020;102:942-5.

3. Center for Disease Control and Prevention. Cases in the U.S. [Internet]. New York, NY: Center for Disease Control and Prevention; c2020 [cited 2020 Apr 9]. Available from: https://www. cdc.gov/coronavirus/2019-ncov/cases-updates/cases-in-us. html?CDC_AA_refVal=https $\% 3 \mathrm{~A} \% 2 \mathrm{~F} \% 2 \mathrm{Fwww} . \mathrm{cdc}$. gov\%2Fcoronavirus\%2F2019-ncov\%2Fcases-in-us.html.

4. Ghebreyesus TA. WHO Director-General's opening remarks at the media briefing on COVID-19 - 11 March 2020 [Internet]. Geneva: World Health Organization; c2020 [cited 2020 Apr 9]. Available from: https://www.who.int/dg/speeches/detail/ who-director-general-s-opening-remarks-at-the-media-briefingon-covid-19---11-march-2020.

5. Prentice B, Taylor L. COVID-19: a message to ASCs [Internet]. Alexandria, VA: Ambulatory Surgery Center Association; c2020 [cited 2020 Apr 9]. Available from: https://www.ascassociation. org/asca/resourcecenter/latestnewsresourcecenter/covid-19/ covid-19-message.

6. Feuer W. WHO officials warn health systems are 'collapsing' under coronavirus: 'This isn't just a bad flu season' [Internet]. Englewood Cliffs, NJ: CNBC; c2020 [cited 2020 Apr 9]. Available from: https://www.cnbc.com/2020/03/20/coronavirus-whosays-health-systems-collapsing-this-isnt-just-a-bad-flu-season. html.

7. Legido-Quigley H, Mateos-Garcia JT, Campos VR, Gea-Sanchez M, Muntaner C, McKee M. The resilience of the Spanish health system against the COVID-19 pandemic. Lancet Public Health 2020;5:e251-2.

8. World Health Organization. Update on coronavirus disease in Indonesia [Internet]. Jakarta: World Health Organization Indonesia; c2020 [cited 2020 Apr 9]. Available from: https:// www.who.int/indonesia/news/novel-coronavirus.

9. Chang Liang Z, Wang W, Murphy D, Po Hui JH. Novel coronavirus and orthopaedic surgery: early experiences from Singapore. J Bone Joint Surg Am 2020;102:745-9.

10. World Health Organization. COVID-19 in the Philippines [Internet]. Manila: World Health Organization Representative Office for the Philippines; c2020 [cited 2020 Apr 9]. Available from: https://www.who.int/philippines/emergencies/covid19-in-the-philippines.

11. Worldometer. Coronavirus Thailand [Internet]. c2020 [cited 2020 Apr 9]. Available from: https://www.worldometers.info/ coronavirus/country/thailand/.

12. Worldometer. Coronavirus Malaysia [Internet]. c2020 [cited 2020 Apr 9]. Available from: https://www.worldometers.info/ coronavirus/country/malaysia?id=15557035.

13. Rochmyaningsih D. Indonesia finally reports two coronavirus cases. Scientists worry it has many more [Internet]. Washington DC: Sciencemag; c2020 [cited 2020 Apr 9]. Available from: https://www.sciencemag.org/news/2020/03/indonesia-finallyreports-two-coronavirus-cases-scientists-worry-it-has-manymore\#.

14. Bishop K. Italy's death toll from the coronavirus overtakes China’s [Internet]. Englewood Cliffs, NJ: CNBC; c2020 [cited 2020 Apr 9]. Available from: https://www.cnbc.com/2020/03/19/ coronavirus-death-toll-italys-is-now-higher-than-chinas.html.

15. Korean Society of Infectious Diseases; Korean Society of Pediatric Infectious Diseases; Korean Society of Epidemiology; Korean Society for Antimicrobial Therapy; Korean Society for Healthcare-associated Infection Control and Prevention; Korea Centers for Disease Control and Prevention. Report on the epidemiological features of coronavirus disease 2019 (COVID-19) outbreak in the Republic of Korea from January 19 to 
March 2, 2020. J Korean Med Sci 2020;35:e112.

16. Lai CC, Wang CY, Wang YH, Hsueh SC, Ko WC, Hsueh PR. Global epidemiology of coronavirus disease 2019 (COVID-19): disease incidence, daily cumulative index, mortality, and their association with country healthcare resources and economic status. Int J Antimicrob Agents 2020;55:105946.

17. McMichael TM, Currie DW, Clark S, Pogosjans S, Kay M, Schwartz NG, et al. Epidemiology of Covid-19 in a long-term care facility in King County, Washington. N Engl J Med 2020; 382:2005-11.

18. Dube R, Bariyo N, Forero J. Africa, Latin America brace as Coronavirus threatens weaker health systems [Internet]. Ely, NV: PrresFrom; c2020 [cited 2020 Apr 9]. Available from: https://pressfrom.info/us/news/world/-400671-africa-latinamerica-brace-as-coronavirus-threatens-weaker-health-systems. html.

19. Ducournau F, Arianni M, Awwad S, Baur EM, Beaulieu JY, Bouloudhnine M, et al. COVID-19: Initial experience of an international group of hand surgeons. Hand Surg Rehabil 2020;39:15966.

20. Rini IS, Aniko G. Rekomendasi pelayanan bedah plastik rekonstruksi dan estetik pada masa pendemi COVID-19. Jakarta: PERAPI; 2020.

21. Jeffers L. ASPS guidance regarding elective and non-essential patient care [Internet]. Arlington Heights, IL: American Society of Plastic Surgeons; c2002 [cited 2020 Apr 9]. Available from: https://www.plasticsurgery.org/for-medical-professionals/ covid19-member-resources/previous-statements.

22. Centers for Medicare and Medicaid Services. CMS releases recommendations on adult elective surgeries, non-essential medical, surgical, and dental procedures during COVID-19 response [Internet]. Baltimore, MD: CMS; c2020 [cited 2020 Apr 9]. Available from: https://www.cms.gov/newsroom/pressreleases/cms-releases-recommendations-adult-elective-surgeriesnon-essential-medical-surgical-and-dental.

23. Richter DF. COVID-19: recommendations for management of elective surgical procedures in aesthetic surgery [Internet]. West Lebanon, NH: International Society of Aesthetic Plastic Surgery; c2020 [cited 2020 Apr 9]. Available from: https:// www.isaps.org/covid-19/covid-19-recommendations-for-management-of-elective-surgical-procedures-in-aesthetic-surgery/.

24. Ruan L, Wen M, Zeng Q, Chen C, Huang S, Yang S, et al. New measures for the coronavirus disease 2019 response: a lesson from the Wenzhou experience. Clin Infect Dis 2020;71:866-9.

25. Yuan ES. A message to our users [Internet]. San Jose, CA: Zoom Video Communications, Inc.; c2020 [cited 2020 Apr 9]. Available from: https://blog.zoom.us/wordpress/2020/04/01/ a-message-to-our-users.
26. DG Alerts. More medical meetings to be held virtually amidst global COVID-19 pandemic [Internet]. c2020 [cited 2020 Apr 9]. Available from: https://dgalerts.docguide.com/ more-medical-meetings-be-held-virtually-amidst-global-covid19-pandemic?nl_ref=newsletter\&pk_campaign=newsletter\&nl_ eventid=36546\&nl_campaignid=3641\&pw_siteID=25\&ncov_ site $=$ covid-19.

27. International Society of Aesthetic Plastic Surgery. Webinars managing global aesthetic practices during COVID-19 [Internet]. West Lebanon, NH: International Society of Aesthetic Plastic Surgery; c2020 [cited 2020 Apr 9]. Available from: https://www.isaps.org/webinars/.

28. Kementerian Kesehatan Republik Indonesia. Standar alat pelindung diri (APD) dalam manajemen penanganan Covid-19. 1st ed. Jakarta: Farmalkes; 2020.

29. van Doremalen N, Bushmaker T, Morris DH, Holbrook MG, Gamble A, Williamson BN, et al. Aerosol and surface stability of SARS-CoV-2 as compared with SARS-CoV-1. N Engl J Med 2020;382:1564-7.

30. Zou L, Ruan F, Huang M, Liang L, Huang H, Hong Z, et al. SARS-CoV-2 viral load in upper respiratory specimens of infected patients. N Engl J Med 2020;382:1177-9.

31. Chan JY, Wong EW, Lam W. Practical aspects of otolaryngologic clinical services during the 2019 novel coronavirus epidemic: an experience in Hong Kong. JAMA Otolaryngol Head Neck Surg 2020;146:519-20.

32. World Health Organization. Rational use of personal protective equipment for coronavirus disease 2019 (COVID-19) [Internet]. Geneva: World Health Organization; c2020 [cited 2020 Apr 9]. Available from: https://apps.who.int/iris/bitstream/handle/10665/331215/WHO-2019-nCov-IPCPPE_use-2020.1eng.pdf.

33. Gillette C, Rudolph M, Kimble C, Rockich-Winston N, Smith L, Broedel-Zaugg K. A meta-analysis of outcomes comparing flipped classroom and lecture. Am J Pharm Educ 2018;82: 6898.

34. Persky AM, McLaughlin JE. The flipped classroom: from theory to practice in health professional education. Am J Pharm Educ 2017;81:118.

35. Chen F, Lui AM, Martinelli SM. A systematic review of the effectiveness of flipped classrooms in medical education. Med Educ 2017;51:585-97.

36. Peeri NC, Shrestha N, Rahman MS, Zaki R, Tan Z, Bibi S, et al. The SARS, MERS and novel coronavirus (COVID-19) epidemics, the newest and biggest global health threats: what lessons have we learned? Int J Epidemiol 2020;49:717-26.

37. Su D, Michaud TL, Estabrooks P, Schwab RJ, Eiland LA, Hansen $G$, et al. Diabetes management through remote patient 
monitoring: the importance of patient activation and engagement with the technology. Telemed J E Health 2019;25:952-9.

38. Portnoy J, Waller M, Elliott T. Telemedicine in the era of COVID-19. J Allergy Clin Immunol Pract 2020;8:1489-91.
39. Greenhalgh T, Wherton J, Shaw S, Morrison C. Video consultations for covid-19. BMJ 2020;368:m998.

40. Hollander JE, Carr BG. Virtually perfect? Telemedicine for Covid-19. N Engl J Med 2020;382:1679-81. 